\title{
Prevalence and factors associated with pulmonary arterial hypertension on maintenance hemodialysis patients in Kinshasa, Democratic Republic of Congo: a cross-sectional study
}

Yannick Mompango Engole ${ }^{1 *}$ (D), François Bompeka Lepira', Yannick Mayamba Nlandu', Yves Simbi Lubenga ${ }^{2}$, Augustin Luzayadio Longo ', Aliocha Nkodila', Jean-Robert Rissassy Makulo', Vieux Momeme Mokoli', Justine Busanga Bukabau', Marie-France Ingole Mboliasa', Evariste Mukendi Kadima', Cedric Kabemba Ilunga', Tresor Swambulu Mvunzi ${ }^{2}$, Nazaire Mangani Nseka ${ }^{1}$ and Ernest Kiswaya Sumaili ${ }^{1}$

\begin{abstract}
Background: Although cardiovascular diseases in particular Pulmonary Arterial Hypertension (PAH) is associated with, high morbid-mortality in chronic hemodialysis, but its magnitude remains paradoxically unknown in subSaharan Africa. The aim of this study was to evaluate the prevalence of PAH and associated factors in chronic hemodialysis in Sub-Saharan African population.
\end{abstract}

Method: In a cross-sectional study, patients treated with HD for at least 6 months in 4 hemodialysis centers were examined. PAH was defined as estimated systolic pulmonary arterial pressure (sPAP) $\geq 35 \mathrm{mmHg}$ using transthoracic Doppler echocardiography performed $24 \mathrm{~h}$ after the HD session.

Results: Eighty-five HD patients were included; their average age was $52.6 \pm 15.9$ years. Fifty-seven patients (67.1\%) were male. Mean duration of HD was $13.3 \pm 11$ months. With reference to vascular access, 12 (14.1\%), 29 (34.1\%) and 44 (51.8\%) patients had AVF, tunneled cuff and temporary catheter, respectively. The underlying cause of ESRD was diabetes in 30 patients (35.3\%). The prevalence of PAH was $29.4 \%$. Patients with PAH had more hyponatremia (11 (44\%) vs $10(16.7 \%), p=0.010)$. In multivariate analysis, unsecured healthcare funding (aOR 4, 95\% Cl [1.186.018]), arrhythmia (aOR 3, 95\% Cl [1.29-7.34]), vascular access change (aOR 4, 95\% Cl [1.18-7.51]) and diastolic dysfunction (aOR 5, 95\% Cl [1.35-9.57] were independently associated with PAH.

Conclusion: One third of hemodialysis patients exhibit PAH, which is independently associated with low socioeconomic status (unsecured funding, vascular access change) and cardiovascular complications (arrhythmia, diastolic dysfunction).

Keywords: Pulmonary hypertension, Hemodialysis, Systolic pulmonary arterial pressure, Cardiovascular disease

\footnotetext{
*Correspondence: yannickengole@yahoo.fr

${ }^{1}$ Nephrology Unit, University Hospital of Kinshasa, Kinshasa, Democratic Republic of the Congo

Full list of author information is available at the end of the article
} 


\section{Background}

Excessive cardiovascular mortality in patients with endstage renal disease (ESRD) has been described in epidemiological and clinical studies. It accounts for about $50 \%$ of deaths in dialysis [1] with a relative excess mortality risk of 2.4 [2]. Pulmonary arterial hypertension (PAH), defined as a rise in pulmonary arterial pressure (PAP) resulting from heart, lung or systemic disorders, is a common finding in patients on maintenance hemodialysis [3, 4] and an independent predictor of all-causes and cardiovascular mortality in maintenance hemodialysis patients [5-8]. The prevalence of $\mathrm{PAH}$ varies from 23 to $33 \%$, as detected by Doppler echocardiography in patients on chronic hemodialysis (HD). Several studies have reported PAH-related mortality: In this regard, the Jackson Heart Study has indicated that PAH was associated with higher risk for heart failure hospitalization and mortality multiplying the Hazard ratio (HR) by 2.37 and 1.84, respectively [9]. In addition, Tang et al. [10] showed that PAH was associated with increased risk for cardiovascular events in patients with CKD (RR 1.67) and ESRD receiving dialysis (RR 2.33). In these patients, PAH may lead to enlarged left atrium, altered arteriovenous fistula (AVF) flow, elevated thromboxane $\beta 2$ and left ventricular diastolic dysfunction [11]. Although the pathogenic mechanism of PAH remains unclear, several factors may cause PAH such as endothelial dysfunction, vascular calcification, diastolic dysfunction, AVF flow, volume overload, left ventricular hypertrophy, dialysis membrane exposures, obstructive sleep apnea syndrome, and pulmonary embolism [12].

To date, there has been no study assess the burden of $\mathrm{PAH}$ on maintenance HD from Sub-Saharan Africa (SSA). Yet, early intervention to reduce pressure in the pulmonary artery can prevent the worsening of heart failure and death [13-16]. Therefore, the present study aimed is to evaluate the prevalence and associated factors of $\mathrm{PAH}$ in chronic hemodialysis in Sub-Saharan African population.

\section{Methods}

\section{Study design and setting}

A cross-sectional study was conducted, between Mars 2016 and June 2019, in 4 hemodialysis centers (Kinshasa University Hospital, Ngaliema Medical center, Afia Medical Care, Medical Center of Kinshasa).

\section{Population study and eligibility criteria}

All consecutive ESRD patients aged $>18$ years old on maintenance $\mathrm{HD}$ for more than 6 months were eligible to participate in this study (Fig. 1). To control potential sources of bias with $\mathrm{PAH}$, patients on chronic hemodialysis with the following characteristics were excluded: chronic pulmonary diseases such as chronic obstructive pulmonary disease, pulmonary fibrosis, pregnant patients, chest wall,

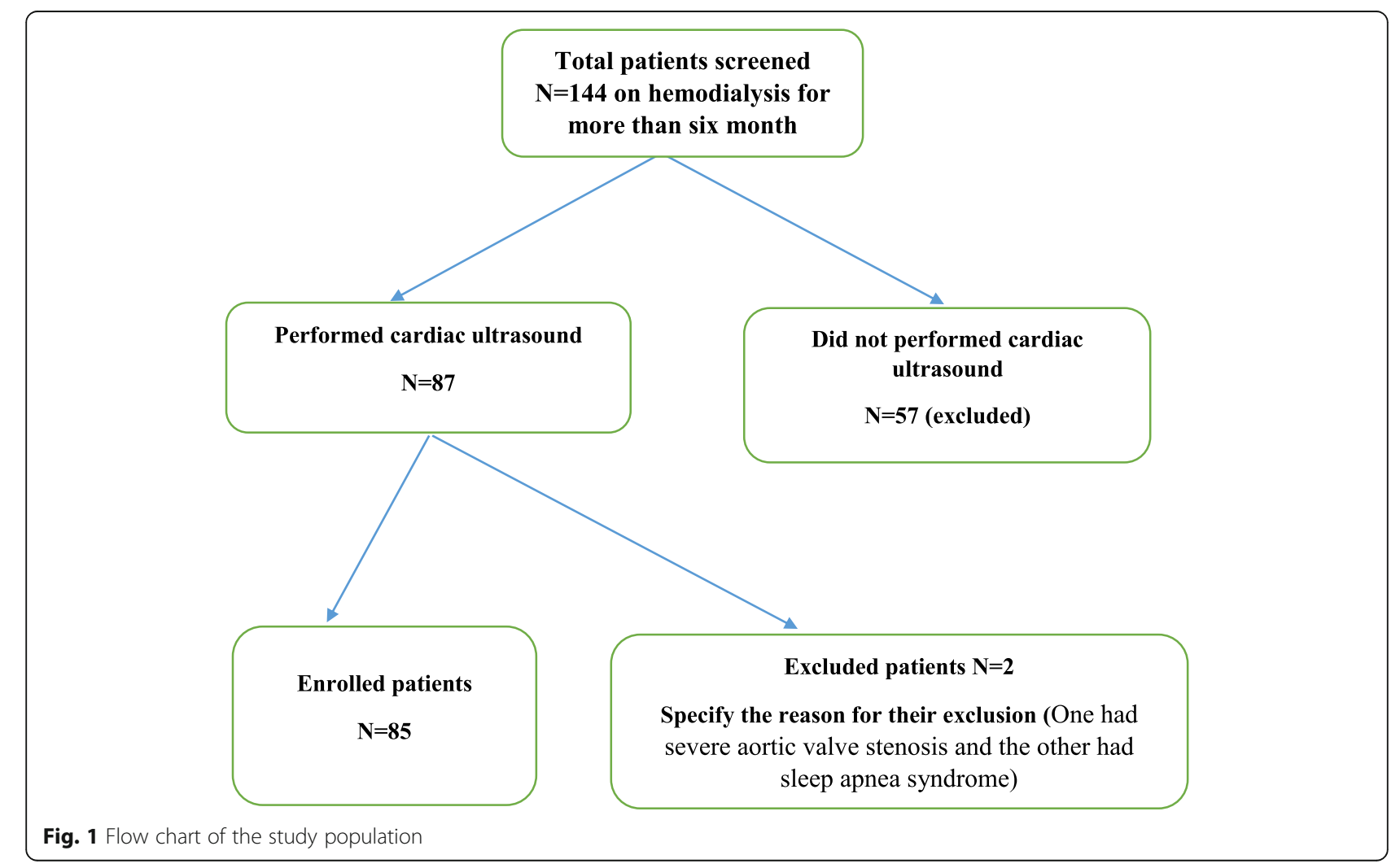


previous pulmonary embolism, collagen vascular disease, moderate or severe mitral or aortic valve disease, severe heart failure and having obstructive sleep apnea syndrome.

\section{Hemodialysis parameters}

Patients had two or three sessions per a week for $24 \mathrm{~h}$ with anticoagulant (low molecular weight heparin or unfractionated heparin) at each session. Most patients were treated with synthetic dialyzer membranes (high flux) and bicarbonate-based on dialysis solution upon a bicarbonate concentration of $32 \mathrm{mEq} / \mathrm{L}$. Blood flow and dialysate flow rate varied between 200 and $400 \mathrm{~mL} / \mathrm{min}$ and $500-800 \mathrm{~mL} / \mathrm{min}$, respectively using 4008 and 5008 $\mathrm{s}$ generators of Fresenius.

\section{Echocardiographic measurements}

Transthoracic Doppler echocardiograms were performed by a single cardiologist using an ultrasound system with a $3.5 \mathrm{~Hz}$ cardiac lead (Vivid 7, GE, Massachusetts, USA) as a non-invasive method, in post dialysis, $24 \mathrm{~h}$ after when patients were on optimal dry weight, PHT was defined as Systolic PAP equal to or greater than $35 \mathrm{mmHg}$. Systolic right ventricular (or pulmonary artery) pressure was calculated using the modified Bernoulli equation: $\mathrm{PAP}=$ tricuspid systolic jet $(\mathrm{TR})+10-15 \mathrm{mmHg}$ (estimated right atrial pressure: $15 \mathrm{mmHg}$ in dilated right atrium and $10 \mathrm{mmHg}$ in normal or slightly enlarged right atrium) [17].

\section{Biological parameters}

Laboratory investigations encompassed: blood urea nitrogen (BUN), serum creatinine, natremia, kaliemia, uric acid, hemoglobin, hematocrit, iron, ferritin, ProBNP, Troponin, calcium, phosphorus, and parathyroid hormone level. The results of the predialysis blood samples at the time of echocardiographic study and the mean of the preceding 3 months values were evaluated.

Others parameters of interest included the following: age, sex, comorbidities, medications, etiology of kidney disease, age at time of ESRD, source of funding, duration of hemodialysis therapy, and blood access location.

\section{Operational definitions}

$\checkmark$ Diastolic dysfunction: was defined as E/A $<1$ or $>2$ and between1-2, additionally with E/E'>15 [18].

$\checkmark$ Systolic dysfunction: LVEF $<55 \%$.

$\checkmark$ Hypervolemia: water retention with tissue infiltration or clinical signs of hyperhydration

$\checkmark$ Hyponatremia is an electrolyte disorder defined by a sodium concentration in the blood plasma of less than $136 \mathrm{mmol} / \mathrm{l}$ [19].

$\checkmark$ Hypocalcemia: electrolyte disorder characterized by an adjusted total serum calcium level of $<8.4 \mathrm{mg} / \mathrm{dl}$ $\checkmark$ Arrhythmia: any rhythm disturbance objectified by the cardiologist during the echocardiography

$\checkmark$ ESRD was defined as irreversible and advanced loss of kidney function due to any etiology requiring long term RRT with HD.

$\checkmark$ Funding was considered secured when health insurance, social security, company or government provided financial support in HD, whereas unsecured healthcare funding as patient without secure financing.

\section{Statistical methods}

All statistical analyses were performed with using SPSS (Statistic Package for Social Sciences) software for Windows version 24.

Data are presented as crude counts (n) and relative (\%) frequencies for categorical variables, as an average $( \pm$ standard deviation) for quantitative variables normally distributed, whereas non-normally distributed are presented as a median (Interquartile range: EIQ). Proportions were compared by the Pearson square Chi-square test or Fischer's exact test as appropriate, whereas means or medians by the Student's t test or the Man Whitney $\mathrm{U}$ test, respectively. Univariate logistic regression analysis was used to identify factors associated with PAH. In order to control the effect of potential confounding, we further performed multivariable logistic regression analysis (using ascending step-by-step approach) to search factors independently associated with PAH. The adjusted ORs and their 95\% CI were calculated finally to determine the degree of association between the PAH and the independent variables. To search for risk factors, two multivariate mathematical models were used to limit the cumulative effect of independent variables. The significance level retained was then $p<0.05$.

\section{Ethical issues}

The research followed the tenets of the Declaration of Helsinki and informed consent was obtained. The Clinical Research Ethics Committee of Kinshasa School of Public Health (number ESP/CE/013/2016) approved the study protocol.

\section{Results}

Eighty-five patients were enrolled in the study; 57 patients $(67.1 \%)$ were male. Mean duration of HD was $13.3 \pm 11$ months. With reference to vascular access, 12 (14.1\%), 29 (34.1\%) and 44 (51.8\%) patients had AVF, tunneled cuff and temporary catheter, respectively. The underlying cause of ESRD was diabetes in 30 patients (35.3\%). Twenty-five (29.4\%) patients (mean age $54.6 \pm$ 14.3 years) had PAH with a mean value for SPAP of $28.0 \pm 10 \mathrm{mmHg}$. 
PAH was present in $25(29.4 \%)$ patients. Patients with PAH had more hyponatremia (11 (44\%) vs 10 (16.7\%), $p=$ $0.010)$, arrhythmia [4 (16\%) vs $1(1.7 \%), p=0.025]$ and had lower $\beta$ blockers [8 (32\%) vs $9(15 \%), p=0.038$ ] and Aspirin junior [15 (60\%) vs $22(36.7 \%), p=0.041]$ than to those without PAH. They also did not have a secure funding $[8$ (32\%) vs $36(60 \%), p=0.017$ ] and experimented a vascular access change [18 (72\%) vs $29(48.3 \%), \mathrm{p}=0.038$ ] (Table 1 ).

Table 1 Characteristics of HD patients according to presence of $\mathrm{PAH}$

\begin{tabular}{|c|c|c|c|}
\hline Variables & $\begin{array}{l}\text { PAH- } \\
n=60\end{array}$ & $\begin{array}{l}\text { PAH+ } \\
n=25\end{array}$ & P-value \\
\hline Male, n (\%) & $39(65.0)$ & $18(72.0)$ & 0.359 \\
\hline Age $\geq 60$ years, $n(\%)$ & $22(36.7)$ & $13(52.0)$ & 0.143 \\
\hline Unemployed, n (\%) & $10(16.7)$ & $2(8.0)$ & 0.600 \\
\hline Secure funding & $36(60.0)$ & $8(32.0)$ & 0.017 \\
\hline HT, n(\%) & $54(90.0)$ & $24(96.0)$ & 0.332 \\
\hline $\mathrm{DM}, \mathrm{n}(\%)$ & $24(40.0)$ & $8(32.0)$ & 0.330 \\
\hline Tabacco, n(\%) & $6(10.0)$ & $4(16.0)$ & 0.329 \\
\hline Alcohol, n(\%) & $14(23.3)$ & $9(36.0)$ & 0.176 \\
\hline Hypervolemia, n(\%) & $31(51.7)$ & $11(44.0)$ & 0.343 \\
\hline Hyponatremia, n(\%) & $10(16.7)$ & $11(44.0)$ & 0.010 \\
\hline Hypocalcemia, n(\%) & $40(66.7)$ & $19(76.0)$ & 0.280 \\
\hline Vascular access, n(\%) & & & 0.248 \\
\hline Temporary catheter & $34(56.7)$ & $10(40.0)$ & \\
\hline Permanent catheter & $20(33.3)$ & $9(36.0)$ & \\
\hline Fistula & $6(10.0)$ & $6(24.0)$ & \\
\hline HD session/week, n(\%) & & & 0.730 \\
\hline 1 & $7(11.7)$ & $3(12.0)$ & \\
\hline 2 & $26(43.3)$ & $13(52.0)$ & \\
\hline 3 & $27(45.0)$ & $9(36.0)$ & \\
\hline Arrhythmia, n (\%) & $1(1.7)$ & $4(16.0)$ & 0.025 \\
\hline Vascular access change, n (\%) & $29(48.3)$ & $18(72.0)$ & 0.038 \\
\hline Supplement Ca/VitD, n (\%) & $31(51.7)$ & $14(56.0)$ & 0.451 \\
\hline Phosphorus chelator, n (\%) & $6(10.0)$ & $5(20.0)$ & 0.183 \\
\hline Diuretic, n (\%) & $30(50.0)$ & $16(64.0)$ & 0.173 \\
\hline EPO, n (\%) & $43(71.7)$ & $19(76.0)$ & 0.451 \\
\hline ACEI, n (\%) & $22(36.7)$ & $14(56.0)$ & 0.081 \\
\hline ARAIl, n (\%) & $12(20.0)$ & $4(16.0)$ & 0.461 \\
\hline$\beta$-blockers, n (\%) & $9(15.0)$ & $8(32.0)$ & 0.038 \\
\hline Iron supplement, n (\%) & $45(75.0)$ & $22(88.0)$ & 0.147 \\
\hline Junior aspirin, n (\%) & $22(36.7)$ & $15(60.0)$ & 0.041 \\
\hline RUV, n (\%) & & & 0.343 \\
\hline$<500 \mathrm{ml}$ & $29(48.3)$ & $14(56.0)$ & \\
\hline$\geq 500 \mathrm{ml}$ & $31(51.7)$ & $11(44.0)$ & \\
\hline
\end{tabular}

Abbreviations: HT Hypertension, DM Diabetes mellitus, HD Hemodialysis, Ca/ VitD Calcium and Vitamin D, EPO Erythropoeitin, ACE Angiotensin conversion enzyme inhibitor, $A R A$ Angiotensin II receptor antagonist, RUV Residual urination volume
Compared with patients without $\mathrm{PAH}$, those with $\mathrm{PAH}$ had, in average, a significantly higher interdialytic weight gain $[(2.8 \pm 1.2)$ vs $(3.4 \pm 1.5)(p=0.014)]$, pulse pressure $[(67.3 \pm 16.7)$ vs $(82.2 \pm 16.8)(p<0.001)]$ (Table 2). These findings were similar to inferior vena cava diameter $(p=$ $0.004)$, filling pressures $\mathrm{E} / \mathrm{E}$ ' $(p=0.001)$ and proportion of diastolic dysfunction $(p=0.007)$ (Table 3$)$.

In logistic multivariate analysis (Table 4), unsecured healthcare funding (aOR 4, 95\% CI [1.18-6.018]), arrhythmia (aOR 3, 95\% CI [1.29-7.34]), vascular access change (aOR 4, 95\% CI [1.18-7.51]) and diastolic dysfunction (aOR 5, 95\% CI [1.35-9.57] were independently associated with $\mathrm{PAH}$.

During the 3 years of follow-up, 4 out of 25 patients with PAH (16\%) had died compared to 18 out of 60 (30\%) without PAH and there was no statistically significant difference between the two groups with a $p=0.263$ (Fig. 2).

\section{Discussion}

The main findings of the present study are as follows. First, roughly 3 out of 10 patients on maintenance hemodialysis had PAH. Second, arrhythmia, vascular access change, diastolic dysfunction and no secure healthcare funding emerged as the main factors independently associated with $\mathrm{PAH}$.

The prevalence of PAH in this study is $29.4 \%$. This value is within the range of $27-57 \%$ reported by most studies $[20,21]$ and similar to that described by Amin et al. [13] in Egypt although echocardiography was performed within $4 \mathrm{~h}$ after the end of dialysis. However, it is lower than the value of 58.6 and $60 \%$ found by Fabian in Italy [22] and Hayati et al. [12] in Iran, respectively, probably, because the latter survey used an average PAP of $25 \mathrm{mmHg}$ to define PAH. The discrepancy between studies in PAH frequency may probably be due to the differences of PAH definition. The criteria of selection and the time to perform the echocardiography relative to hemodialysis session. In this regard, the high $\mathrm{PAH}$ frequency reported by Hayati et al. [23] could be explained by the use of an average PAP of $25 \mathrm{mmHg}$ to define PAH. Having retained the same definition criteria as Ramasubbu et al. [12], namely a systolic PAP $\geq 35$ $\mathrm{mmHg}$, the differences in the sample used and the methodology applied were the reasons for having a low prevalence compared to $47 \%$ of their series. The time of echocardiography realization and the importance of interdialytic weight gain (IWG) could also influence the prevalence of PAH. Similar to our study, echocardiography was performed within $24 \mathrm{~h}$ after the end of dialysis [15]. When pulmonary hypertension was defined as systolic pulmonary arterial pressure (sPAP) $\geq 45 \mathrm{mmHg}$, the frequency of PAH was only 20\% [12]. This may justify 
Table 2 Clinical, biological parameters according to presence of PAH

\begin{tabular}{|c|c|c|c|}
\hline Variables & PAH- & $\mathrm{PAH}+$ & $P$-value \\
\hline Age (years) & $52.0 \pm 16.5$ & $54.6 \pm 14.3$ & 0.482 \\
\hline KTN weekly & $1.1 \pm 0.2$ & $1.1 \pm 0.1$ & 0.960 \\
\hline Dry weight, Kg & $70.5 \pm 16.3$ & $66.9 \pm 14.9$ & 0.354 \\
\hline IWG max kg & $2.8 \pm 1.2$ & $3.4 \pm 1.5$ & 0.014 \\
\hline Pre-dialysis SBP mmHg & $153.0 \pm 18.1$ & $164.0 \pm 18.2$ & 0.012 \\
\hline Pre-dialysis DBP mmHg & $85.6 \pm 15.5$ & $81.9 \pm 14.8$ & 0.311 \\
\hline PP mmHg & $67.3 \pm 16.7$ & $82.2 \pm 16.8$ & $<0.001$ \\
\hline Duration in $\mathrm{HD}$, month & $14.4 \pm 12.2$ & $18.5 \pm 10.2$ & 0.264 \\
\hline $\mathrm{BMI}, \mathrm{kg} / \mathrm{m}^{2}$ & $25.5 \pm 5.4$ & $24.6 \pm 4.6$ & 0.503 \\
\hline Residual diuresis, mL & $625.0(241.0-1010.0)$ & 774,0 (370.0-1680.0) & 0.711 \\
\hline Creatinin, mg/dL & $9.7 \pm 3.2$ & $9.9 \pm 4.4$ & 0.804 \\
\hline $\mathrm{BUN}, \mathrm{mg} / \mathrm{dL}$ & $139.2 \pm 51.9$ & $147.3 \pm 56.6$ & 0.525 \\
\hline Uric Acid, mg/dL & $7.3 \pm 1.9$ & $7.6 \pm 2.0$ & 0.560 \\
\hline $\mathrm{Na}^{+}, \mathrm{mmol} / \mathrm{L}$ & $134.7 \pm 2.5$ & $132.5 \pm 3.4$ & 0.048 \\
\hline $\mathrm{K}^{+}, \mathrm{méq} / \mathrm{L}$ & $4.6 \pm 0.6$ & $4.6 \pm 0.6$ & 0.949 \\
\hline $\mathrm{P} \times \mathrm{Ca}_{1}{ }^{2} \mathrm{mg}^{2} / \mathrm{dL}^{2}$ & $42.8 \pm 12.9$ & $44.5 \pm 16.0$ & 0.607 \\
\hline Albumin, $g / L$ & $36.3 \pm 5.9$ & $36.1 \pm 5.4$ & 0.876 \\
\hline $\mathrm{Hb} \mathrm{g} / \mathrm{dL}$ & $9.0 \pm 1.6$ & $8.8 \pm 1.0$ & 0.509 \\
\hline $\mathrm{Hct}, \%$ & $27.2 \pm 5.3$ & $26.7 \pm 3.6$ & 0.672 \\
\hline Total Cholesterol, mg/dL & $172.2 \pm 38.7$ & $183.7 \pm 29.7$ & 0.188 \\
\hline $\mathrm{HDL}-\mathrm{c}, \mathrm{mg} / \mathrm{dL}$ & $45.5 \pm 17.1$ & $50.1 \pm 21.5$ & 0.298 \\
\hline $\mathrm{LDL}-\mathrm{c}, \mathrm{mg} / \mathrm{dL}$ & $103.4 \pm 33.3$ & $118.4 \pm 32.3$ & 0.060 \\
\hline Triglyceride, mg/dL & $114.2 \pm 40.6$ & $118.6 \pm 37.2$ & 0.642 \\
\hline Vit $\mathrm{D}, \mathrm{ng} / \mathrm{mL}$ & $27,3(0,0-35,0)$ & $26.9(10.4-38.5)$ & 0.132 \\
\hline PTH, pg/mL & $379,3(197,6-509,0)$ & $282.9(16.1-1308.6)$ & 0.886 \\
\hline Ferritin, ng/mL & $339.5(45.5-20,000)$ & 458.4 (212.4-2000.0) & 0.817 \\
\hline S. Iron, $\mu \mathrm{mol} / \mathrm{L}$ & $12.8(10.2-14.5)$ & $13.1(9.5-24.9)$ & 0.705 \\
\hline Troponin, ng/L & $15.4(1.5-48.0)$ & $16.4(7.6-34.0)$ & 0.670 \\
\hline ProBNP, pg/mL & $5907.0(1509-22,222)$ & $12,846.0(4548-25,000)$ & 0.425 \\
\hline CRP mg/L & $33.3(0.6-76.0)$ & 18.5 (1.9-112.0) & 0.186 \\
\hline
\end{tabular}

Data are expressed as mean \pm standard deviations (ET), crude ( $n$ ) and relative frequency (in percent)

Abbreviations: SBP systolic blood pressure, DBP diastolic blood pressure, PP pulse pressure, BMI body mass index, IWG interdialytic weight gain, eGFR estimated glomerular filtration rate, $M D R D$ modification of diet in renal disease, $B U N$ blood urea nitrogen, $P x C a$ phosphate calcium product, $P T H$ parathormon, $H D L-c$ highdensity lipoprotein-cholesterol, $L D L-c$ low-density lipoprotein-cholesterol, ProBNP Pro brain natriuretic peptid

our high prevalence compared to the value of $16 \%$ reported by Agarwal et al. [6].

Possible explanations of PAH in long term hemodialysis patients can be grouped into 3 categories: 1) a volumetric overload caused by increased cardiac output following an arteriovenous fistula, anemia or hypervolemia [24, 25]; 2) barometric overload, a consequence of the increase in pulmonary vascular resistance caused by endothelial dysfunction induced by uremia, pulmonary embolism, calcification of the pulmonary artery or other comorbid diseases,

including pulmonary disease chronic obstructive or connective tissue disease, and 3) an increase in pulmonary capillary pressure caused by systolic and diastole in heart failure [8]. Some authors have claimed that microbubbles originating from dialyzers can also become embedded in the pulmonary blood circuit and cause an increase in pressure in the pulmonary circulation [26].

The independent determinants of pulmonary arterial hypertension in our study were unsecured funding for dialysis, arrhythmia, vascular access first change, and diastolic dysfunction. The positive association of unsecured funding (due to low socioeconomic status) with PAH reflects irregular dialysis sessions with subsequent significant interdialytic weight gain through renal sodium and water retention [22]. Sodium and water retention and subsequent hemodilution may also explain 
Table 3 Echocardiography parameters according to presence $\mathrm{PAH}$

\begin{tabular}{llll}
\hline Variables & PAH- & PAH + & P value \\
\hline IVS & $13.1 \pm 2.4$ & $13.6 \pm 2.1$ & 0.340 \\
LVPW & $11.8 \pm 1.9$ & $12,9 \pm 2.8$ & $\mathbf{0 . 0 3 9}$ \\
LVEF & $64.5 \pm 8.6$ & $64.3 \pm 10.3$ & 0.942 \\
LVEDD & $49.9 \pm 6.1$ & $50.4 \pm 5.8$ & 0.737 \\
LVMi & $369.4 \pm 139.6$ & $367.0 \pm 170.9$ & 0.948 \\
ICV & $13.6 \pm 4.9$ & $17.2 \pm 5.6$ & $\mathbf{0 . 0 0 4}$ \\
E/A & $1.0 \pm 0.6$ & $1.3 \pm 0.9$ & 0.118 \\
E/E' & $9.5 \pm 4.1$ & $14.0 \pm 7.2$ & $\mathbf{0 . 0 0 1}$ \\
SPAP & $23.1 \pm 6.1$ & $42.2 \pm 6.9$ & $<\mathbf{0 . 0 0 1}$ \\
DT & $217.2 \pm 45.9$ & $243.4 \pm 104.9$ & 0.276 \\
Left Atrium volume & $20.6 \pm 5.3$ & $22.9 \pm 6.4$ & 0.080 \\
Right Atrium volume & $14.8 \pm 3.0$ & $18.2 \pm 4.5$ & $<\mathbf{0 . 0 0 1}$ \\
RVEDD & $20.1 \pm 6.3$ & $21.2 \pm 7.8$ & 0.505 \\
Calcifications & $19(31.7)$ & $9(36.0)$ & 0.442 \\
Systolic dysfunction & $17(28.3)$ & $10(40.0)$ & 0.211 \\
Diastolic dysfunction & $8(14.8)$ & $6(35.3)$ & $\mathbf{0 . 0 0 7}$ \\
Pericardial effusion & $9(15.0)$ & $3(12.0)$ & 0.506 \\
\hline
\end{tabular}

IVS interventricular septum, LVPWd left ventricular posterior wall in diastolic, LVEF left ventricular ejection fraction, LVEDD left ventricular end diastolic diameter, $L V M I$ left ventricular mass index, ICV inferior cave veinous, $D T$ deceleration time; SPAP systolic pressure arterial pulmonary

hyponatremia that may explain its significant difference in patients with $\mathrm{PAH}$, although it did not persist after adjusting for funding, hyponatremia and arrhythmia. The increase in free water due to the increase in antidiuretic hormone (Vasopressin) can also be responsible for hyponatremia [19]. The vascular access change, most often from catheter to more efficient vascular access such as arteriovenous fistula aggravates the pulmonary congestion through increased circulating blood volume. This lack of care is also the cause of a late referral, justifying the fact that several patients start hemodialysis in disaster with a temporary catheter that they find it difficult to change after lack of financial sources. Indeed, Indeed, Arterio-venous fistula, the ideal approach in hemodialysis, associated with anemia and hypervolemia largely contribute to increasing cardiac venous return, which in turn will lead to a barometric increase in the pulmonary artery $[27,28]$. There are many parameters that participate in diastolic heart failure, among which long-term arterial hypertension in chronic dialysis patients is the basis of an increase in left ventricular mass, a defect in relaxation of the left ventricle with elevated blood pressure filling. The loss of vascular elasticity and the proliferation of myocytes found in many diabetic patients is also one of the major causes [29]. Diastolic dysfunction, with a rise in filling pressures resulting in post-capillary $\mathrm{PAH}$, could also explain the observed association with PAH. Our finding showing an association between diastolic dysfunction and PAH corroborate with that reported by Abdelwhab et al. [11], Abedini et al. [29] and Agarwal [6]; the latter found an increased left atrium diameter. The finding of our study point out the role of volumetric overload in the pathogenesis of $\mathrm{PAH}$ among maintenance hemodialysis patients. Other studies identified increased age [12], female [13], lower body mass index [12], high cardiac output [25], lower hemoglobin [24], lower metabolites of nitric oxide [25], upper dialysis cycle [22], and lower diastolic blood pressure [22] as additional factors associated with PAH.

In the present study patients with PAH had elevated E/E ratio and ProBNP level suggesting a chronic volume overload and subsequent diastolic dysfunction [9]. This chronic volume overload translated in increased inferior vena cava diameter at exhalation that could be the probable cause of an association between an elevated right atrial diameter and PAH. Chronic volume overload was more frequent in patients with suboptimal dialysis and subsequent increased interdialytic weight gain related to irregular dialysis sessions favored by unsecured funding. In fact, in previous studies, a decrease in PAP following short AV fistula compression [24], as well as fluid

Table 4 Factors associated with PAH in univariate and multivariate logistic regression analysis

\begin{tabular}{|c|c|c|c|c|}
\hline \multirow[t]{2}{*}{ Variables } & \multicolumn{2}{|c|}{ Univariate analysis } & \multicolumn{2}{|c|}{ Multivariate analysis } \\
\hline & $p$-value & unadjustedOR (IC95\%) & $p$-value & aOR (IC95\%) \\
\hline \multicolumn{5}{|l|}{ Model 1} \\
\hline Healthcare funding (no secured vs yes) & 0.021 & $3.19(1.19-8.55)$ & 0.026 & $3.91(1.18-6.010)$ \\
\hline Hyponatremia (no vs yes) & 0.010 & $3.93(1.39-11.13)$ & 0.085 & $2.81(0.87-5.13)$ \\
\hline Arrhythmia (no vs yes) & 0.035 & $4.24(1.19-6.33)$ & 0.030 & $3.15(1.29-7.34)$ \\
\hline \multicolumn{5}{|l|}{ Model 2} \\
\hline$\beta$-blockers (no vs yes) & 0.018 & $2.67(1.89-8.01)$ & 0.251 & $1.98(0.62-6.39)$ \\
\hline Junior aspirin (no vs yes) & 0.015 & $2.59(1.99-6.75)$ & 0.094 & $2.36(0.86-6.44)$ \\
\hline Vascular access change (no vs yes) & 0.041 & $2.75(1.02-7.54)$ & 0.034 & $4.02(1.18-7.51)$ \\
\hline Diastolic dysfunction (no vs yes) & 0.007 & $3.14(2.90-10.91)$ & 0.011 & $4.98(1.35-9.57)$ \\
\hline
\end{tabular}




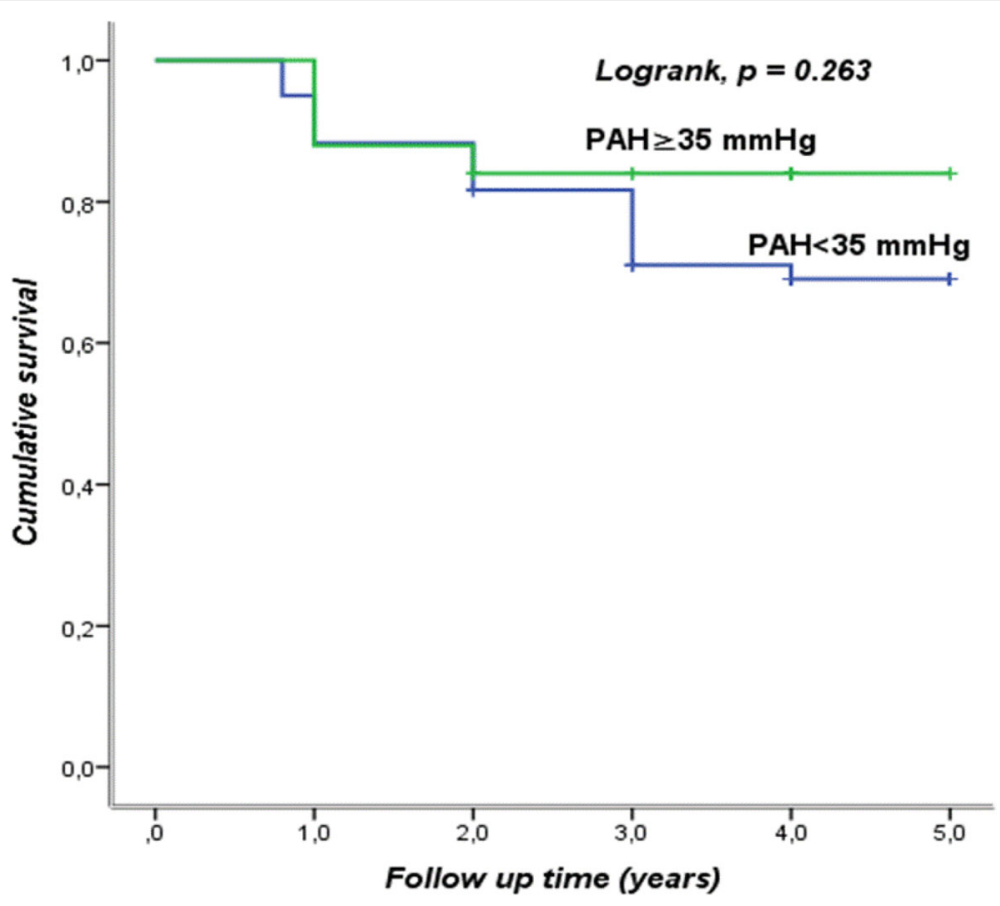

Fig. 2 Survival curve

removal, has been reported [30]. The use of the diuretics and inhibitors of Renin Angiotensin Aldosterone system may therefore be associated with lower pulmonary hypertension (although we did not find a difference in LV mass index between groups). Except from abovementioned hemodynamic factors, biochemical factors could also contribute to $\mathrm{PAH}$ in maintenance hemodialysis patients. In this regard, an increase in circulating nitric oxide synthase inhibitors like asymmetric dimethyl arginine (ADMA) accumulate with subsequent poor availability of nitric oxide, oxidative stress, endothelial dysfunction and vasoconstriction that can worsen PAH [25]. Increased stiffness of the pulmonary capillaries due to hyperparathyroidism and pulmonary vascular calcification is one possible explanation for the occurrence of PAH [31]. As expected, we did not establish an association between pulmonary arterial hypertension, calcium, phosphorus and parathyroid [20,32]. That is because our patients were younger, with lesser duration of HD, cardiovascular diseases and comorbidities than those published elsewhere.

\section{Study limitations}

The interpretation of the results of the present study should take into account of some limitations. First, the cross-sectional design of the study precludes the establishment of temporal relationship between the issues of interest. Second, the small sample size did not allow sufficient power to statistical tests to identify potential associations between variables of interest.
Third, the unique measurement of parameters of interest could have over- or underestimated their true values. Fourth, computerized tomography was not performed to exclude other potential causes of PAH.

\section{Conclusion}

$\mathrm{PAH}$, was a common clinical finding in the present case series and affects more than one in four patients on maintenance hemodialysis in sub-Saharan African.

\section{Abbreviations}

CHF: Congestive Heart Failure; DM: Diabetes Mellitus; EF: Ejection Fraction; ESRD: End Stage Renal Disease; GFR: Glomerular Filtration Rate; HD: Hemodialysis; HT: hypertension; IVC: Inferior Vena Cava; IVS: Interventricular Septum; LV: Left Ventricle; LVEDD: Left Ventricle End Diastolic Diameter; LVESD: Left Ventricle End Systolic Diameter; LVH: Left Ventricular Hypertrophy; LVMi: Left Ventricular Mass index; LVPW: Left Ventricular Posterior Wall; RUV: Residual urination volume; PAH: Pulmonary Arterial hypertension; sPAP: systolic Pulmonary Arterial Pression

\section{Acknowledgements}

The authors wish to thank the various hemodialysis centers for collecting data.

\section{Authors' contributions}

All authors of the manuscript participated in the conduct and preparation of the study. YE, FL and ES designed the study, acquired, analyzed and interpreted data, drafted and revised the manuscript. AL, AN, YN, J-RM, VM, JB, MF-M, TM, YL, FK, AN, CI, EK, NN and ES analyzed, interpreted data and revised the manuscript. The author(s) read and approved the final manuscript.

Authors' information

'Not applicable'. 


\section{Funding}

This work received no financial assistance from any funding agency in the public, commercial, or non-profit sectors.

\section{Availability of data and materials}

The datasets used and/or analysed during the current study are available from the corresponding author on reasonable request.

\section{Ethics approval and consent to participate}

The research followed the tenets of the Declaration of Helsinki. We obtained verbal informed consent from all participants and administrative permission from each hemodialysis center for data collection. The Clinical Research Ethics Committee of Kinshasa School of Public Health (number ESP/CE/013/ 2016) approved the protocol of this cross-sectional study.

\section{Consent for publication}

'Not applicable'.

\section{Competing interests}

The authors declare that they do not have any financial interest with the information contained in this paper.

\section{Author details}

'Nephrology Unit, University Hospital of Kinshasa, Kinshasa, Democratic Republic of the Congo. ${ }^{2}$ Cardiology Unit, University Hospital of Kinshasa, BP: 123, Kinshasa, XI, Democratic Republic of the Congo.

\section{Received: 7 January 2020 Accepted: 27 October 2020}

\section{Published online: 04 November 2020}

\section{References}

1. United States Renal Data System. Excerpts from USRDS 2005 annual data report. US Am J Kidney Dis. 2006;47:S1-286.

2. Reque J, Garcia-Prieto A, Linares T, Vega A, Abad S, Panizo N, et al. Pulmonary hypertension is associated with mortality and cardiovascular events in chronic kidney disease patients. Am J Nephrol. 2017:45:107-14.

3. Archer S, Rich S. Primary pulmonary hypertension: a vascular biology and translational research "work in progress". Circulation. 2000;102:2781-91.

4. Yigla M, Dabbah S, Azzam ZS, Rubin AH, Reisner SA. Background diseases in 671 patients with moderate to severe pulmonary hypertension. Isr Med Assoc J. 2000;2:684-9.

5. Li Z, Liu S, Liang X, Wang W, Fei H, Hu P, et al. Pulmonary hypertension as an independent predictor of cardiovascular mortality and events in hemodialysis patients. Int Urol Nephrol. 2014;46:141-9.

6. Agarwal R. Prevalence, determinants and prognosis of pulmonary hypertension among hemodialysis patients. Nephrol Dial Transplant. 2012; 27:3908-14.

7. Issa N, Krowka MJ, Griffin MD, Hickson LJ, Stegall MD, Cosio FG. Pulmonary hypertension is associated with reduced patient survival after kidney transplantation. Transplantation. 2008;86:1384-8.

8. Sise ME, Courtwright AM, Channick RN. Pulmonary hypertension in patients with chronic and end-stage kidney disease. Kidney Int. 2013;84:682-92.

9. Selvaraj S, Shah SJ, Ommerborn MJ, Clark CR, Hall ME, Mentz RJ, et al. Pulmonary hypertension is associated with a higher risk of heart failure hospitalization and mortality in patients with chronic kidney disease: the Jackson heart study. Circ Heart Fail. 2017;10:e003940.

10. Tang M, Batty JA, Lin C, Fan X, Chan KE, Kalim S. Pulmonary hypertension, mortality, and cardiovascular disease in CKD and ESRD patients: a systematic review and meta-analysis. Am J Kidney Dis. 2018;72:75-83.

11. Abdelwhab S, Elshinnawy S. Pulmonary hypertension in chronic renal failure patients. Am J Nephrol. 2008;28:990-7.

12. Ramasubbu K, Deswal A, Herdejurgen C, Aguilar D, Frost AE. A prospective echocardiographic evaluation of pulmonary hypertension in chronic hemodialysis patients in the United States: prevalence and clinical significance. Int J Gen Med. 2010;3:279-86.

13. Amin M, Fawzy A, Hamid MA, Elhendy A. Pulmonary hypertension in patients with chronic renal failure: role of parathyroid hormone and pulmonary artery calcifications. Chest. 2003;124:2093-7.

14. Bossone E, Bodini BD, Mazza A, Allegra L. Pulmonary arterial hypertension: the key role of echocardiography. Chest. 2005;127:1836-43.
15. Abolghasemi R, Sang-Sefidi J, Miri R, Soluki M. Pulmonary hypertension in chronic hemodialysis patients. Iran J Kidney Dis. 2007:9.

16. Reisner SA, Azzam Z, Halmann M, Rinkevich D, Sideman S, Markiewicz W, et al. Septal/free wall curvature ratio: a noninvasive index of pulmonary arterial pressure. J Am Soc Echocardiogr. 1994;7:27-35.

17. Dabestani A, Mahan G, Gardin JM, Takenaka K, Burn C, Allfie A, et al. Evaluation of pulmonary artery pressure and resistance by pulsed Doppler echocardiography. Am J Cardiol. 1987;59:662-8.

18. Vignon P. Evaluation des pressions de remplissage gauche par échocardiographie doppler. Science Direct. 2007;10:101.

19. Hoorn EJ, Zietse R. Diagnosis and treatment of hyponatremia: compilation of the guidelines. J Am Soc Nephrol. 2017;28:1340-9.

20. Tarrass F, Benjelloun M, Medkouri G, Hachim K, Benghanem MG, Ramdani B. Doppler echocardiograph evaluation of pulmonary hypertension in patients undergoing hemodialysis. Hemodial Int. 2006;10:356-9.

21. Havlucu Y, Kursat S, Ekmekci C, Celik P, Serter S, Bayturan O, et al. Pulmonary hypertension in patients with chronic renal failure. Respiration. 2007;74:503-10

22. Fabbian F, Cantelli S, Molino C, Pala M, Longhini C, Portaluppi F. Pulmonary hypertension in dialysis patients: a cross-sectional italian study. Int J Nephrol. 2010;2011:283475.

23. Hayati F, Beladi Mousavi SS, Mousavi Movahed SM, Mofrad BM. Pulmonary hypertension among patients undergoing hemodialysis. J Renal Inj Prev. 2017;6:122-6.

24. Yigla M, Nakhoul F, Sabag A, Tov N, Gorevich B, Abassi Z, et al. Pulmonary hypertension in patients with end-stage renal disease. Chest. 2003;123: $1577-82$.

25. Nakhoul F, Yigla M, Gilman R, Reisner SA, Abassi Z. The pathogenesis of pulmonary hypertension in haemodialysis patients via arterio-venous access. Nephrol Dial Transplant. 2005;20:1686-92.

26. Barak M, Katz Y. Microbubbles: pathophysiology and clinical implications. Chest. 2005;128:2918-32.

27. Unal A, Tasdemir K, Oymak S, Duran M, Kocyigit I, Oguz F, et al. The longterm effects of arteriovenous fistula creation on the development of pulmonary hypertension in hemodialysis patients. Hemodial Int. 2010;14: 398-402.

28. Liefeldt L, van Giersbergen PL, Dingemanse J, Rudolph B, Walde T, Budde K, et al. Treatment of secondary pulmonary hypertension with bosentan and its pharmacokinetic monitoring in ESRD. Am J Kidney Dis. 2004;43:923-6.

29. Abedini M, Sadeghi M, Naini AE, Atapour A, Golshahi J. Pulmonary hypertension among patients on dialysis and kidney transplant recipients. Ren Fail. 2013;35:560-5.

30. Palecek T, Skalicka L, Lachmanova J, Tesar V, Linhart A. Effect of preload reduction by hemodialysis on conventional and novel echocardiographic parameters of left ventricular structure and function. Echocardiography. 2008;25:162-8.

31. Akmal M, Barndt RR, Ansari AN, Mohler JG, Massry SG. Excess PTH in CRF induces pulmonary calcification, pulmonary hypertension and right ventricular hypertrophy. Kidney Int. 1995;47:158-63.

32. Mahdavi-Mazdeh M, Alijavad-Mousavi S, Yahyazadeh H, Azadi M, Yoosefnejad H, Ataiipoor Y. Pulmonary hypertension in hemodialysis patients. Saudi J Kidney Dis Transplant. 2008;19:189.

\section{Publisher's Note}

Springer Nature remains neutral with regard to jurisdictional claims in published maps and institutional affiliations.

Ready to submit your research? Choose BMC and benefit from:

- fast, convenient online submission

- thorough peer review by experienced researchers in your field

- rapid publication on acceptance

- support for research data, including large and complex data types

- gold Open Access which fosters wider collaboration and increased citations

- maximum visibility for your research: over $100 \mathrm{M}$ website views per year

At $\mathrm{BMC}$, research is always in progress.

Learn more biomedcentral.com/submissions 